\title{
Conhecimento dos usuários, trabalhadores da saúde e gestores sobre conselheiros e Conselhos de Saúde
}

\author{
Knowledge of users, workers and managers about Health Councils and councilors
}

Camila Sartori Martins'; Michele Thaís Sartori²; Helena Luiza Douat Dietrich33; Fabiane Barbero Klem; Camilo Dallagnol ${ }^{5}$; Guilherme Souza Cavalcanti de Albuquerque ${ }^{6}$; Paulo de Oliveira Perna ${ }^{7}$; Samya Mehanna ${ }^{8}$

${ }^{1}$ Graduanda em Medicina pela Universidade Federal do Paraná (UFPR) - Curitiba (PR).

pinkmila@gmail.com

${ }^{2}$ Graduanda em Medicina pela Universidade Federal do Paraná (UFPR) - Curitiba (PR).

michelisarts@yahoo.com.br

${ }^{3}$ Graduanda em Medicina pela Universidade Federal do Paraná (UFPR) - Curitiba (PR).

helena.dietrich@yahoo.com.br

${ }^{4}$ Graduanda em Medicina pela Universidade Federal do Paraná (UFPR) - Curitiba (PR).

fabianeklem@gmail.com

${ }^{5}$ Graduando em Medicina pela Universidade Federal do Paraná (UFPR) Curitiba (PR).

c_dallagnol@hotmail.com.

${ }^{6}$ Doutor em Educação pela Universidade Federal do Paraná (UFPR) - Curitiba (PR). Professor do Departamento de Saúde Comunitária da Universidade Federal do Paraná (UFPR) - Curitiba (PR). guilherme.albuquerque@ufpr.br

${ }^{7}$ Mestre em Enfermagem pela Universidade Federal de Santa Catarina (UFSC) - Florianópolis (SC), Brasil. Professor do Departamento de Enfermagem da Universidade Federal do Paraná. Pesquisador do Núcleo de Estudos em Saúde Coletiva da Universidade Federal do Paraná (UFPR) Curitiba (PR).

perna@ufpr.br

${ }^{8}$ Graduanda em Medicina pela Universidade Federal do Paraná (UFPR) - Curitiba (PR). samya1988@yahoo.com.br.
RESUMO: A criação de um espaço democrático de participação na condução do Sistema Único de Saúde (SUS) constituiu indubitável conquista dos brasileiros. O pleno exercício deste direito implica, no entanto, no conhecimento do próprio direito, dos espaços e dos mecanismos de participação, que permitam uma ação autônoma. No presente trabalho avalia-se o grau de conhecimento nos diversos segmentos sociais acerca da questão. Foram entrevistados usuários e trabalhadores do SUS, além de membros dos Conselhos de Saúde. Os resultados demonstram grande desinformação dos usuários, dos novos conseIheiros e da maioria dos trabalhadores, em contraste com os gestores e os conselheiros com mais tempo no cargo

PALAVRAS-CHAVE: Controle Social; Conselho de Saúde; Conselheiros de Saúde; SUS; Participação Social.

ABSTRACT: The creation of a democratic space for participation in the conduction of the Sistema Único de Saúde ( SUS) - Brazilian Public Health Care System - was undoubtedly an achievement for Brazilians. Full exercise of this right implies, however, knowledge of the right itself, spaces and mechanisms for participation, allowing for autonomous action. The present study evaluates the degree of knowledge in the various social segments on this issue. Users and workers of SUS health care units were interviewed as well as members of Health Councils. Results show misinformation from most councilors and health workers when compared to managers and advisors who have worked longer in their positions

KEYWORDS: Social Control; Health Councils; Councilors; SUS; Social Participation. 


\section{Introdução}

Em uma sociedade de classes, a ação do Estado, agente de reprodução e controle segundo os interesses da classe dominante (ALTHUSSER, 1999), é resultante das tensóes que os interesses das diversas classes exercem sobre ele. Em seu papel de preservar a hegemonia, o Estado responde aos interesses populares nas situaçóes que coincidem com os interesses das classes dominantes, ou diante da necessidade de ceder aos anseios das classes subalternas, visando manter a aceitação da ordem estabelecida. É nesses espaços de contradição que os avanços reformistas - ou seja, não revolucionários - das conquistas populares podem ocorrer. Assim, no movimento de reforma do Estado brasileiro, formalizado pela Constituição de 1988, espaços institucionalizados de disputa dos interesses dos diversos segmentos da sociedade foram estabelecidos, constituindo, apesar das limitações citadas, inegável avanço em relação ao Estado ditatorial militar.

O estabelecimento de um espaço de participação popular se deu no âmbito da saúde, no Brasil, desde a década de 1950, com a representaçáo da sociedade civil no Conselho Nacional de Saúde. Na década de 1980, porém, no bojo da luta pela redemocratização do País, a participação avançou significativamente através da ação de movimentos sociais, que se desenvolviam em várias frentes de luta, culminando com avanços na formulação da nova constituição.

Com a Constituinte, a participação popular na elaboração, acompanhamento e fiscalização das políticas públicas ganha institucionalidade, já que a Carta prevê a criação de instâncias específicas com este fim, obrigatórias no caso de setores onde existem fundos a serem geridos, como saúde e educação (MATEOS, 2011).

A Constituição da República Federativa do Brasil, de 1988, estabeleceu, no inciso III, do artigo 198, seção II (DA SAÚDE), a 'participação da comunidade' como uma das diretrizes do Sistema Único de Saúde.

Em nosso país criaram-se, a partir de então, Conselhos e Conferências de Saúde como espaços privilegiados de proposição e controle das açóes do setor. Os movimentos sociais, cuja ação esteve represada durante os longos anos da ditadura militar, passaram, a partir de então, a encontrar um espaço de manifestação, mesmo que dentro dos limites do Estado.

A participação popular na elaboração, implementação e fiscalização das políticas públicas vem tomando uma dimensão sem precedentes, possibilitando, de alguma forma, o aumento da eficácia e abrangência das açóes públicas, assim como da capacidade de formulação dos movimentos sociais (MATEOS, 2011).

No âmbito da Saúde, a regulamentação específica destes espaços se deu com a Lei no 8142 , de 1990, que legitimou a atuação dos conselhos na formulação de estratégias e no controle da execução das políticas de saúde na instância correspondente, inclusive nos aspectos econômicos e financeiros. Segundo a referida lei:

$\int 2^{\circ}$ O Conselho de Saúde, em caráter perma-
nente e deliberativo, órgáo colegiado composto
por representantes do governo, prestadores de
serviço, profissionais de saúde e usuários, atua
na formulação de estratégias e no controle da
execuçâo da política de saúde na instância cor-
respondente, inclusive nos aspectos econômicos
e financeiros, cujas decisóes serão homologa-
das pelo chefe do poder legalmente constituído
em cada esfera do governo (BRASIL. Lei no
8142 , de 28 de dezembro de 1990).

Dentro do processo de descentralização da saúde, a criação dos Conselhos de Saúde passou a ser uma exigência para o repasse de recursos da esfera federal para as esferas estaduais e municipais. Diante disso, criaram-se muitos conselhos como mera formalidade para viabilizar o recebimento dos recursos. Estes conselhos, forjados pelo Estado, caracterizam-se majoritariamente pela manipulação de sua composição, ingerência dos gestores e atuação inexpressiva no sentido de aprovar documentos para repasse de recursos (SPOSATI; LOBO, 1992). Assim, apesar de ter sido formada uma extensa rede de Conselhos de Saúde, essa não propiciou participação efetiva dos diversos segmentos sociais. Logo, o ganho quantitativo não foi acompanhado por uma melhora qualitativa na participação popular na saúde. Diversos autores que avaliam o desempenho e o papel real exercido pelos Conselhos de Saúde, desta forma (SPOSATI; LOBO, 
1992; ABRASCO, 1993; COHN; ELIAS; JACOBI, 1993; CARVALHO, 1995; ANDRADE, 1996; VIANA, 1998; CARNEIRO, 2002; MÜLLER NETO et al., 2006), acreditam que esses órgãos influenciam minimamente a incorporação das demandas das parcelas não hegemônicas da sociedade às políticas de saúde. Para eles, essa situação decorre principalmente da tradição autoritária do Estado brasileiro, o que, frequentemente, dificulta o reconhecimento e o respeito ao direito dos cidadáos; da fragilidade da vida associativa; e da própria resistência ou dificuldade dos atores sociais em participar de arenas de discussão (SPOSATI; LOBO, 1992; ABRASCO, 1993; COHN; ELIAS; JACOBI, 1993; CARVALHO, 1995; ANDRADE, 1996; VIANA, 1998; CARNEIRO, 2002). Dentro dos conselhos, os próprios representantes dos segmentos dos usuários e dos trabalhadores, destituídos de tantos recursos quanto os que têm os representantes das classes hegemônicas, cumprem, em sua maioria, papel meramente formal.

Crucial, no entanto, na determinação da participação social é a questão da formação do conselheiro, no sentido de provê-lo das informaçóes necessárias para uma intervenção qualificada na construção de um posicionamento que represente os anseios do segmento que ele representa e na defesa do mesmo. Nesse sentido, diversas iniciativas têm ocorrido, em várias regiōes do País, visando a formação de conselheiros de saúde, através de cursos, oficinas, encontros promovidos - seja pela instância municipal, estadual ou federal do SUS, seja pelas universidades ou pela iniciativa dos próprios Conselhos -, induzidos pelo Conselho Nacional de Saúde com sua deliberação sobre a educação continuada dos conselheiros.

Apesar desse processo de formação, as demandas das conferências de saúde não têm sido satisfatoriamente inseridas na agenda de prioridades dos governos municipais (MÜLLER NETO et al., 2006) e, de acordo com pesquisa realizada no Rio de Janeiro, grande parte dos conselheiros desconhece seu papel, o que os torna facilmente manipuláveis (GERSCHMANN, 2004).

Originado pela necessidade de obter dados e informaçóes que subsidiem açóes para superar alguns destes entraves, o presente estudo visa aferir o grau de conhecimento dos usuários, trabalhadores e gestores de saúde, bem como dos representantes desses segmentos no Conselho Municipal de Saúde do Município de Colombo, localizado no Estado do Paraná.

\section{Método}

Realizou-se um estudo transversal, a partir de entrevista semiestruturada, aplicada a usuários e trabalhadores de Unidades de Saúde (US) e conselheiros do Conselho Municipal de Saúde (CMS). Os entrevistados assinaram previamente o Termo de Consentimento Livre e Esclarecido, sendo suas respostas gravadas, transcritas e posteriormente desgravadas.

A pesquisa foi realizada em 4 das 21 US de Colombo, escolhidas por constituírem campo de estágio e extensão para os estudantes da instituição de ensino superior envolvida.

Os participantes foram selecionados de acordo com os seguintes critérios: ser usuário ou trabalhador de US e estar presente no horário de atendimento das mesmas, durante o período de realização da pesquisa; ser gestor público de saúde do município; ou ser membro dos Conselhos Locais de Saúde ou do CMS. O critério de exclusão foi a recusa do sujeito em participar da pesquisa.

$\mathrm{Na}$ amostra inicial foram incluídos todos os trabalhadores de saúde das 4 US, de um total de 144 (36, em média, por US); 120 usuários, distribuídos igualmente entre as 4 US; 10 membros dos Conselhos Locais, existentes em apenas 2 US; 10 membros do CMS; e 10 gestores de saúde do Município de Colombo (PR), totalizando 294 sujeitos a serem entrevistados.

Dos 144 trabalhadores de saúde que compuseram a amostra, somente foram entrevistados 95, porque os demais, por algum motivo, não se encontravam em atividade durante o período de realização das entrevistas. Os usuários entrevistados totalizaram 120, atendendo integralmente ao número planejado. Dos 10 conselheiros municipais foram entrevistados apenas 3, pois somente estes compareceram à reunião do CMS na data agendada para a entrevista. Nenhum dos conselheiros locais foi entrevistado, pois as reunióes dos Conselhos Locais de Saúde foram suspensas por motivos diversos durante o período de realização das entrevistas. 
Os dados coletados foram sistematizados e categorizados de modo a permitir uma análise sobre o conhecimento dos representantes dos diversos segmentos quanto aos direitos e ao papel dos conselheiros e quanto à finalidade e ao modo de funcionamento do conselho. Os participantes foram identificados como $\mathrm{T}$ (trabalhadores), $\mathrm{U}$ (usuários) e $\mathrm{G}$ (gestores e conselheiros).

Este estudo foi aprovado pelo Comitê de Ética em Pesquisa da Universidade Federal do Paraná (UFPR) sob o número 0085.0.091.000-09.

\section{Resultados}

\subsection{TRABALHADORES DA SAÚDE}

Dentre os trabalhadores de saúde, 41 eram agentes comunitários de saúde (ACS); 11, técnicos (1 de farmácia, 4 de higiene bucal e 6 de enfermagem); 8, auxiliares de serviços gerais; 11 , profissionais cursando a Residência Multiprofissional em Saúde da Família (3 nutricionistas, 3 odontólogos, 2 enfermeiros, 2 farmacêuticos e 1 médico); além de 10 enfermeiros, 7 médicos, 6 odontologistas e 1 fisioterapeuta do quadro permanente da Secretaria Municipal da Saúde (SMS).

Com relação aos 41 ACS, 26 possuíam ensino médio completo; 5 , ensino médio incompleto; 5 , ensino fundamental incompleto; e 1 deles possuía ensino superior completo. Do total, 30 não participavam de qualquer grupo associativo e 6 nunca haviam escutado falar em Conselho de Saúde. Dentre os 35 que tinham alguma informação, 20 já haviam participado de alguma reunião de conselho, porém, como membro efetivo, somente 3, que, mesmo nesta condição, nunca haviam recebido qualquer capacitação.

Sobre a natureza do Conselho de Saúde, somente 1 deles soube responder corretamente em que consiste o mesmo, 10 não souberam responder, 4 disseram que se tratava de um órgão responsável por fiscalizar os gastos de saúde, 6 afirmaram tratar-se de uma reuniáo com o intuito de orientar hábitos de vida saudáveis aos usuários e outros 14 responderam que é o local de participação da população. Sobre o funcionamento do conselho, 16 não souberam responder e 19 afirmaram que os conselhos realizavam as suas reunióes para divulgar as melhorias que acontecem nas US e os hábitos de saúde no bairro.

Quanto ao papel dos conselheiros, 13 ACS responderam que é o de fiscalizar as reunióes dos conselhos ou dar ideias de prevenção; 21 não souberam responder e somente 1 disse que era o de participar da formulação de políticas públicas de saúde, fiscalizar gastos, prazos e resultados.

Em relação aos direitos dos conselheiros, 22 afirmaram desconhecer o assunto, 13 responderam que o conselheiro não tem poder e que seu direito se restringe a eleger alguém para participar da Conferência de Saúde.

Acerca da composição do conselho, 30 afirmavam desconhecer o assunto, 3 sabiam apontar somente os segmentos indicados pela legislação (usuários, gestores e trabalhadores de saúde), sem precisar a quantidade, e 2 conheciam tanto os segmentos mencionados quanto os percentuais de cada um. No que diz respeito ao papel dos conselheiros que representam os trabalhadores do SUS, 8 responderam corretamente. Os outros 27 entrevistados que já haviam ouvido falar do Conselho de Saúde afirmaram desconhecer o papel do conselheiro representante do seu segmento (trabalhadores do SUS) ou achavam que o conselheiro não tinha papel algum definido.

Foram entrevistados 11 técnicos, das áreas de Farmácia, Odontologia e Enfermagem. Apenas um possuía ensino fundamental completo e os demais haviam cursado o ensino médio completo. Nenhum participava de grupo ou entidade associativa; três deles desconheciam completamente em que consistia o Conselho de Saúde. Entre os oito que já haviam ouvido falar sobre o Conselho de Saúde, quatro não souberam responder o restante do questionário. Apenas um respondeu todas as perguntas corretamente. Os dez restantes desconheciam a composição do Conselho de Saúde e o papel dos conselheiros; três deles responderam que a função do Conselho de Saúde era a prestação de contas da US para a população.

Do conjunto de oito auxiliares de serviços gerais entrevistados, um possuía ensino superior completo e sete haviam completado apenas o ensino médio. Um deles participava de um grupo associativo, entretanto, não houve diferença de conteúdo em suas respostas para com as dos demais. 
Seis deles já haviam escutado falar do Conselho de Saúde, todavia, como já observado entre os técnicos, somente um respondeu todo o questionário corretamente. Os demais desconheciam o papel dos conselheiros e do conselho, bem como sua composição.

Os 11 membros da Residência Multiprofissional em Saúde da Família apresentaram um padrão de resposta exemplar. Registre-se que nenhum residente foi, alguma vez, membro de qualquer Conselho de Saúde. Todos já tinham ouvido falar em Conselho de Saúde, porém dois residentes de Odontologia responderam que não sabiam o que era e nunca tinham participado de qualquer reuniấo do Conselho. Os outros nove responderam todas as perguntas corretamente; alguns, ainda, agregaram a sua resposta observaçóes que demonstravam seu conhecimento sobre os problemas de funcionamento do conselho como, por exemplo:

Em teoria, deveria ser algo democrático, porém, na prática, a força política influencia muito. Os trabalhadores e usuários participam pouco. Os gestores dominam. Deveriam ser decisóes de comum acordo (T6).

E, por fim, dos 24 trabalhadores restantes - médicos, dentistas, farmacêuticos e enfermeiros - somente 3 participavam de algum grupo associativo. De modo geral, apresentaram respostas semelhantes às dos ACS.

Dos 20 destes trabalhadores, que já tinham ouvido falar do Conselho de Saúde e, ao serem interrogados sobre o que é o conselho, 4 não souberam responder, 10 afirmaram que são reuniôes onde se discutem questôes de saúde ou outros problemas da comunidade, e os outros 6 responderam corretamente. Sobre o funcionamento do conselho, nove nada sabiam, três afirmavam tratar-se somente de reuniōes e oito responderam acertadamente.

Quando questionados sobre os conselheiros de saúde, 7 conheciam o papel/função de um conselheiro, 13 desconheciam e alguns apontaram como funções do conselheiro açóes como ter ideias de programas de saúde. Sobre os direitos dos conselheiros, dez afirmavam nada saber, seis responderam corretamente e quatro disseram que os conselheiros não têm poderes.
Já sobre a composição dos Conselhos de Saúde, somente sete souberam indicar de forma correta os segmentos sociais que os compóem e em que percentuais; quatro conheciam somente os segmentos; e nove desconheciam tanto os segmentos quanto os percentuais. Nove destes trabalhadores nunca haviam comparecido a qualquer reunião; três já haviam sido conselheiros, mas nunca receberam qualquer capacitação. Quanto ao papel do segmento dos trabalhadores nos conselhos, 13 afirmaram desconhecê-lo e 7 disseram que seu papel seria o de levar ao conselho propostas e sugestóes, bem como defender os interesses dos trabalhadores de saúde.

Observou-se o mesmo padrão nas respostas de trabalhadores que não participavam de grupos associativos e nas daqueles que participavam.

\subsection{USUÁRIOS}

Foram entrevistados 120 usuários de distintos graus de instrução: desde os que nunca haviam frequentado a escola até os que possuíam o terceiro grau completo, sendo que 46 possuíam ensino fundamental incompleto; 24, o ensino fundamental completo; 22, o ensino médio incompleto; e 25, o ensino médio completo. A maioria deles, 112 (93,33\%), não participava de qualquer grupo associativo. No entanto, não se observou diferença no padrão de resposta desses em relação às respostas dos oito que afirmaram fazer parte de alguma associação.

Em relação ao vínculo empregatício, no momento da pesquisa, 54 usuários estavam trabalhando, sendo quase todos trabalhadores domésticos, sem carteira assinada. Dos demais 66 participantes, 34 eram donas de casa, 17 eram aposentados e 15 afirmaram estar desempregados.

Dos 120 usuários entrevistados, 79 (65,8\%) desconheciam a existência dos Conselhos de Saúde. Dentre os 41 que já tinham ouvido falar, 26 responderam que não sabiam do que se tratava e 5 entendiam o conselho como um espaço de aconselhamento da população sobre os cuidados à saúde, como se observa na seguinte resposta:

São pessoas que andam lutando e lidando para a melhora da saúde das pessoas, alertando as pessoas, porque tem muita gente que não se cuida (U12). 
Outros dois entendiam o Conselho de Saúde como um conselho gestor, tendo um deles afirmado que "os conselhos comandam o postinho"(U22).

Os oito restantes responderam que o Conselho de Saúde era um meio de fiscalização e/ou encaminhamento de reclamações e exigências da população.

Os usuários entrevistados desconheciam o funcionamento do Conselho de Saúde. Apenas três responderam corretamente e somente um sabia da frequência das reuniōes e conhecia a composição do mesmo. A maioria dos que responderam a esta última questão apenas citava a participação dos médicos e da população.

Somente dois deles conheciam o papel do conselheiro de saúde e oito conheciam os seus direitos. Muitos dos que desconheciam o que era o conselho deduziam seu papel da denominação 'conselho' como sendo o de aconselhamento sobre medidas para o autocuidado, tal como se evidencia na afirmação abaixo:

\section{Aconselhar a população, indicando procedi- mentos de prevenção de doenças" (U31).}

Do total de 120 usuários entrevistados, 11 haviam participado de alguma reuniâo de Conselho de Saúde, 6 dos quais em reunióes de Conselho Local. Dentre os que já haviam participado de alguma reuniāo, cinco o haviam feito na condição de conselheiros, representando o segmento dos usuários. Apenas um havia participado de atividades de capacitação para o cargo, sendo o único a responder satisfatoriamente a todas as questóes.

\subsection{GESTORES E MEMBROS DO CONSELHO MU- NICIPAL DE SAÚDE}

Deste grupo foram entrevistados três gestores e nove conselheiros do CMS de Colombo (PR). Com relação aos conselheiros, quatro representavam os usuários do SUS; três, os trabalhadores da saúde; e dois, os prestadores de serviços. Observou-se grande divergência no padrão de respostas entre estes subgrupos.

O grau de escolaridade dos conselheiros representantes dos usuários era bastante heterogêneo: dois possuíam ensino superior completo, um havia cursado o fundamental completo e o outro nunca havia frequentado a escola. Dentre eles, dois não sabiam responder nenhuma das questôes relativas ao Conselho de Saúde e apresentaram como justificativa o fato de estarem há pouco tempo no cargo, acrescentando que esperavam aprender no próprio processo, através da prática. Estes conselheiros afirmaram ter assumido o cargo por determinação do grupo associativo no qual estavam inseridos.

Os outros dois representantes dos usuários já ocupavam havia muito tempo o cargo de conselheiros. Afirmavam que a função dos conselheiros limitava-se a de fiscalizar, uma vez que esta era a finalidade do próprio Conselho de Saúde. Somente um deles havia participado de curso de capacitação promovido pela Prefeitura Municipal em 2008, que, no entanto, tratava apenas de cuidados à saúde.

Os três representantes dos trabalhadores de saúde eram ACS com ensino médio completo, sendo que nenhum participava de grupos associativos. Dois deles não souberam responder às perguntas e o outro soube falar de suas funçóes e direitos, mas desconhecia a função do conselho, conforme se verifica em sua manifestação:

\section{Acredito que as reuniōes são repasses das infor-} maçôes discutidas pelos gestores (G3).

Nenhum dos três conselheiros representantes dos trabalhadores de saúde havia participado de cursos de capacitação para a função.

Entre os conselheiros representantes dos prestadores de serviço, um possuía o ensino médio completo e era presidente do Sindicado dos Servidores Municipais de Colombo, enquanto o outro possuía ensino superior completo e não participava de nenhum grupo associativo. Ambos responderam que o Conselho de Saúde era um meio de fiscalizar a saúde. Em relação a sua função e ao seu direito como conselheiro, responderam que era o de fiscalizar. Ambos afirmaram ter assistido palestra de capacitação para exercerem essa função.

As respostas dos representantes dos gestores foram bastante homogêneas. Todos possuíam ensino superior completo, sendo dois funcionários da Secretaria Municipal da Saúde e um da Secretaria Municipal da Fazenda. Apenas um participava de uma associação (Sindicato dos Servidores). Quando questionados sobre o 
Conselho de Saúde, os três convergiram para a ideia de que se trata de uma instância de controle social:

\section{É o espaço que permite à sociedade participar da gestão. É responsável por acompanhar qual- quer ação dos postos de saúde e patrimônio do município.}

Além disso, os três sabiam como funciona e como é composto o Conselho de Saúde. As respostas sobre o papel do conselheiro e seus direitos foram iguais, apontando para fiscalização e proposta de novas açôes. Especificamente sobre o papel do gestor no Conselho de Saúde, dois deles responderam que era o de repassar dados sobre os gastos e um respondeu que era o de fiscalizar. Nenhum deles afirmou ter realizado qualquer curso de capacitação.

\section{Discussão}

Entre os usuários e trabalhadores de saúde entrevistados é notória a diferença de escolaridade média, sendo os trabalhadores, em geral, mais escolarizados. Diferenças no grau de escolaridade podem interferir no grau de mobilização e representatividade destes grupos, pois podem determinar diferentes graus de conhecimento, recursos técnicos e mesmo de linguagem (LABRA, 2002; TATAGIBA, 2002; VAN STRALEN et al., 2006; COELHO, 2004). Como os conselheiros de menor poder aquisitivo costumam apresentar-se em desvantagem em relação a essas questôes, continuarão excluídos e com grande dificuldade para articular, defender e encaminhar suas demandas.

No presente estudo, grande parte dos conselheiros respondeu que sua principal função é a de fiscalizar. Isto revela certo grau de imaturidade, pois, como proferido por Oliveira e Almeida (2009, p. 150) em relação a membros de conselho gestor, ao longo do tempo eles "clarificam seu papel e passam de fiscalizadores a deliberadores, com maior capacitação ao poder em termos técnico-administrativos e operacionais".

Mesmo com o intuito de exercer o papel de fiscalizadores, a maior parte dos conselheiros representantes de segmentos dos usuários e trabalhadores de saúde náo consegue ter uma boa noção de questóes como o orçamento da saúde e, desta forma, qualquer ideia ou proposta apresentada pelo segmento dos gestores é, em geral, aceita sem questionamentos. Assim, verifica-se que "ter acesso à informaçâo sem apropriar-se de seu significado, sentido e contexto empobrece o potencial de uso da informação nas discussóes sobre as políticas de saúde" (CARVALHO, 1995).

Ao contrário de outras pesquisas que apontam uma tendência para uma verdadeira 'profissionalizaçâo' do conselheiro, pela longa permanência na função (OLIVEIRA; ALMEIDA, 2009; VAN STRALEN et al., 2006; COELHO, 2004), o que se verificou no presente estudo foi uma elevada rotatividade dos conselheiros. Estes, na maioria das vezes, assumem o cargo desconhecendo quase que completamente seu papel, esperando aprendê-lo na prática, durante o desempenho de sua função. Assim, como afirma Gerschmann (2004), o aprendizado é muitas vezes empírico e passível de manipulação por quem o detém. O conhecimento, sujeito a tais distorçôes, distanciado da ideologia e dos interesses dos segmentos representados, limita a possibilidade de intervenção autônoma e a possibilidade de uma real representatividade no conselho.

São os representantes dos gestores que conseguem impor o direcionamento que lhes interessa. Como afirma Ammann (1985, p. 47), com base numa análise gramsciana em relação à participação social, os técnicos

[...] operam na qualidade de funcionários da superestrutura, contribuindo, neste caso, para que as classes subordinadas permaneçam à margem do processo decisório da sociedade global e que, mediante o acesso a decisóes adjetivas locais tenham a ilusão de estarem de fato participando. Por esta via os intelectuais colaboram para o 'consentimento espontâneo das grandes massas da população à direção impressa à vida social pelo grupo fundamental dominante.

De fato, este tipo de dinâmica que se reproduz no Brasil contemporâneo inviabiliza uma participação social entendida como um "processo mediante o qual as diversas camadas sociais tomem parte na produção, na gestão e 
no usufruto dos bens de uma sociedade historicamente determinada" (AMMANN, 1985, p. 17). As grandes diferenças sociais, próprias das sociedades de classe, como pondera Mészáros (2002), impedem um controle consciente da dinâmica social por parte da classe submetida, o que seria indispensável para tornar as relaçóes sociais favoráveis à máxima realização humana. Em outros termos, essa conquista é estruturalmente incompatível em sociedades organizadas para a produção/reprodução do capital.

Para Mészáros, ainda, a instituição do controle social nos termos propostos acima só poderá ocorrer como consequência de transformação radical da sociedade, no sentido de voltá-la para o interesse das pessoas não mais divididas em classes:

\section{[...] o estabelecimento do novo modo de controle} social é inseparável da realização dos princípios de uma 'economia socialista, centrada numa significativa economia da atividade produtiva, pedra angular de uma rica realização humana numa sociedade emancipada das instituiçóes de controle alienadas e reificadas (MÉSZÁROS, 2002, p. 1010, destaques no original).

Se adotarmos os limites impostos pelo modo de produção vigente, resta-nos ou a busca de consensos possíveis, substituindo a relação de oposição dos interesses entre capital e trabalho pelas relações consensuais criadas pelas argumentaçóes discursivas desenvolvidas no 'mundo da vida', como propõe Habermas (MONTAÑO; DURIGUETTO, 2011), ou então, a volta à crença na 'vontade comum', como afirma Rousseau.

Nestes termos, mais honestos nos parecem os liberais que, inspirados em Tocqueville, explicitam que, em sua visão, o governo cabe aos capazes e as associaçóes livres, à maioria do povo, para satisfazer seus anseios de participação.

Como ponderamos anteriormente, a atuação prática dos conselheiros lhes permite desenvolver conhecimento - técnico e político -, mas empírico, limitado à aparência dos fenômenos, no âmbito do senso comum. É necessário, pois, que esse conhecimento seja trabalhado em suas relaçôes teóricas, em especial, na aproximação da filosofia, conferindo ao sujeito uma capacidade maior de autonomia, tanto técnica como política. Não de uma filosofia especulativa sobre o real, mas uma filosofia crítica, conforme a visão marxiana, que trabalhe com as dimensôes dialética e histórica, fundamentais para os sujeitos que visam à transformação da realidade.

Com base nisso, a decisão de organizar um programa de formação continuada de conselheiros deveria ser uma das diretrizes do Conselho de Saúde. Para alcançar a superação do senso comum pela filosofia (GRAMSCI, 1984), a formação dos conselheiros deve avançar para conteúdos tanto de base política como técnica, alicerçados não em qualquer referência filosófica, mas naquela que auxilie o trabalhador a conhecer e fundamentar sua condição de classe.

\section{Conclusões}

Conclui-se, a partir deste estudo, que, mesmos nos estreitos limites de participação impostos pela sociedade capitalista, a falta de conhecimento dos conselheiros de saúde reduz ainda mais suas possibilidades de ação. Os representantes de todos os segmentos entrevistados não conhecem suficientemente o papel tanto do conselho quanto do conselheiro de saúde. O grau de conhecimento é maior entre os gestores do SUS, o que lhes confere maior poder de influência no direcionamento das políticas de saúde.

O estudo não evidenciou a relação do grau de conhecimento com a participação em grupos associativos, nem com a escolaridade dos entrevistados. A maioria dos conselheiros de saúde não recebeu capacitação para exercer o cargo.

Se existe alguma pretensão de que a participação social no SUS contribua para a construção de uma sociedade na qual todos os grupos sociais participem da produção, da gestão e do usufruto dos bens produzidos, é imperativo dar acesso, aos conselheiros, ao conhecimento necessário para uma ação transformadora consciente, que alavanque a reestruturação radical no sentido de uma sociedade mais saudável. Conhecimento técnico e, principalmente, político, compreendendo política como a luta pelo poder para o alcance dos objetivos da classe ou fração de classe representada. 


\section{Referências}

ABRASCO. Relatório final da oficina: incentivo à participação popular e controle social em saúde, Série Saúde e Movimento, v. 1, Brasília: Abrasco, 1993.

ALTHUSSER, L. Sobre a reprodução. Petrópolis: Vozes, 1999.

AMMANN, S. B. Ideologia do desenvolvimento de comunidade no Brasil. São Paulo: Cortez, 1985.

ANDRADE, I. A. L. de. Descentralização e poder municipal no nordeste: os dois lados da moeda. In: ANPOCS, 1996, Caxambu. 20 Encontro Nacional da ANPOCS, 1996.

BRASIL. Lei 8.142, de 28 de dezembro de 1990. Dispõe sobre a participação da comunidade na gestão do Sistema Único de Saúde (SUS) e sobre as transferências intergovernamentais de recursos financeiros na área da saúde e dá outras providências. Diário Oficial da União, Brasília, 28 dez 1990.

Constituição (1988). Constituição da República Federativa do Brasil. Disponível em: <http://www.planalto.gov.br/ccivil_03/ Constituicao/Constituiçao.htm\#cfart198>. Acesso em 3 mai. 2012.

. Lei no 8142, de 28 de dezembro de 1990. Disponível em: <http://www.planalto.gov.br/ccivil_03/leis/L8142.htm>. Acesso em 3 maio 2012.

CARNEIRO, C. B. L. Conselhos: uma reflexão sobre os condicionantes de sua atuação e os desafios de sua efetivação. Informativo CEPAM. v. 1, n. 3, 2002, p. 62-70. Fundação Prefeito Faria Lima. São Paulo. Brasil.

CARVALHO, A. I. Conselhos de saúde no Brasil: participação cidadã e controle social. Rio de Janeiro: IBAM/FASE; 1995.

COELHO, V. S. P. Conselhos de saúde enquanto instituições políticas: o que está faltando. In: COELHO, V. S. P; NOBRE, M. (Org). Participação e deliberação: teoria democrática e experiências institucionais no Brasil contemporâneo. São Paulo: Ed. 34; 2004; p. 255-269.

COHN, A; ELIAS, P.; JACOBI, P. Participação popular e gestão de serviços de saúde: um olhar sobre a experiência do município de São Paulo. Revista Saúde em Debate, n. 38, 1993, p. 90-93.

GERSCHMANN, S. Conselhos municipais de saúde: atuação e representação das comunidades populares. Cadernos de. Saúde Pública. , v. 20, n. 6, 2004, p. 1670-1680.
GRAMSCI, A. Concepção dialética da história, 5 ed., Rio de Janeiro: Civilização Brasileira, 1984.

LABRA, M. E.; FIGUEIREDO, J. S. A. Associativismo, participação e cultura cívica: o potencial dos Conselhos de Saúde. Ciência e Saúde Coletiva, v. 7, n. 3, 2002, p. 537-547.

MATEOS, S. B. A construção da democracia participativa. Desafios do Desenvolvimento, Brasília, n. 65, 2011, p. 18-33.

MÉSZÁROS, I. Para além do capital: rumo a uma teoria da transição. São Paulo: Boitempo Editorial, 2002.

MONTAÑO, C; DURIGUETTO, M. L. Estado, classe e movimento social. 2. ed. São Paulo: Cortez, 2011.

MÜLLER NETO, J. S. et al. Conferências de saúde e formulação de políticas em 16 municípios de Mato Grosso, 2003-2005. Saúde em Debate, v. 30, n. 73/74, 2006, p. 248-274.

OLIVEIRA, M. L.; ALMEIDA, E. S. Controle social e gestão participativa em saúde pública em unidades de saúde do município de Campo Grande, MS, 1994-2002. Saúde e Sociedade, v. 18, n. 1, 2009, p. 141-153.

SPOSATI A.; LOBO, E. Controle social e políticas públicas. Cadernos de Saúde Pública, v. 4, n. 8, 1992, p. 366-378.

TATAGIBA, L. A. Institucionalização da participação: os conselhos municipais de políticas públicas na cidade de São Paulo. São Paulo: 2002.

VAN STRALEN, C. J. et al. Conselhos de Saúde: efetividade do controle social em municípios de Goiás e Mato Grosso do Sul. Ciência e Saúde Coletiva, v. 11, n. 3, 2006, p. 621-632.

VIANA, A. L. Desenho, modo de operação e representação dos interesses do sistema municipal de saúde e os conselhos de saúde. Ciência e Saúde Coletiva, v. 3, n. 1, 1998, p. 20-23.

Recebido para publicação em setembro de 2012

Versão definitiva em dezembro de 2013

Suporte financeiro: não houve

Conflito de interesse: inexistente 